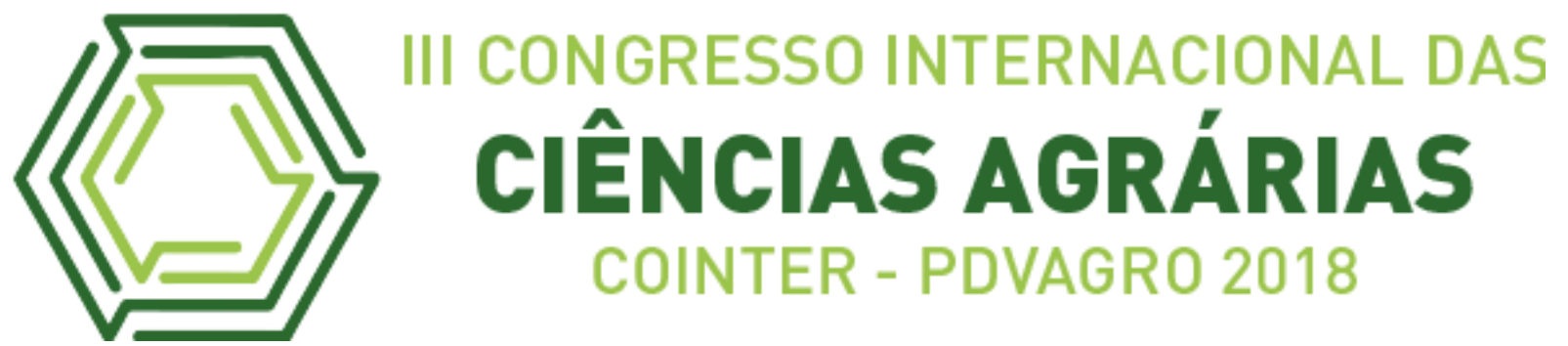

\title{
SUSTENTATIBILIDADE AMBIENTAL: CULTIVANDO SABERES NO ESPAÇO ESCOLAR INFANTIL
}

\section{ENVIRONMENTAL SUSTAINABILITY: PRODUCING KNOWLEDGE IN CHILDREN'S SCHOOL SPACE}

Apresentação: Relato de Experiência

João Henrique Constantino Sales Silva ${ }^{1}$; Maria José Araújo Wanderley ${ }^{2}$; Gilvaneide Alves de Azeredo ${ }^{3}$

DOI: https://doi.org/10.31692/2526-7701.IIICOINTERPDVAGRO.2018.00780

\section{Introdução}

Atualmente, discute-se muito sobre meio ambiente e sua importância quando consideramos que a população está ficando cada vez mais urbanizada e tendo menos contato com os recursos naturais, como o solo, as plantas e a água em seus mananciais de origem (BENTO et al., 2018). De acordo com esses autores, com esse afastamento do campo, as crianças aprendem o que é meio ambiente apenas na teoria e muitas não se sentem parte dele.

As práticas ecológicas estão relacionadas aos conceitos de cidadania e desenvolvimento sustentável, resgatando o papel de agente transformador do ser humano (SOUZA et al., 2013). Ainda segundo esses autores, essas práticas são maneiras de agir visando à preservação do meio ambiente e a melhor utilização dos recursos disponíveis, diminuindo assim, os impactos ambientais.

A Educação Ambiental é, portanto, um assunto que deve ser abordado continuamente pelos diversos setores da sociedade, sobretudo na escola, de modo que desperte o senso crítico dos educandos a fim de sensibilizá-los às práticas de conservação e respeito ao espaço coletivo em que vivem, conscientizando-os de que dependemos do ambiente para nossa sobrevivência (CABRAL et al, 2015).

Ante ao exposto, o presente trabalho objetiva relatar uma experiência vivenciada numa escola pública com discentes da Educação Infantil, mediante uma oficina de Educação Ambiental a partir da confecção de uma horta sustentável.

\footnotetext{
${ }^{1}$ Bacharelado em Agroecologia, CCHSA/UFPB, joaohenriqueconst@gmail.com

${ }^{2}$ Professora doutora, CCHSA/UFPB, mjwander@gmail.com

${ }^{3}$ Professora doutora, CCHSA/UFPB, azeredogil@yahoo.com.br
} 


\section{Relato de Experiência}

A oficina foi realizada no dia 18 de outubro do decorrente ano na Escola de Educação Infantil Donzinha Bezerra, situada no município de Bananeiras/PB. Esta atividade prática constituiu-se como uma ação de extensão do projeto intitulado: "Boas práticas alimentares no convívio infantil (Probex 2018)", coordenado pela Prof Dr $^{\mathrm{a}}$ Maria José Araújo Wanderley. A oficina tinha como objetivo proporcionar aos discentes uma visão holística acerca do cultivo/propagação de hortaliças e sensibilizá-los quanto a importância da reutilização de material (recipiente) que seria descartado ao meio ambiente para a produção de mudas de hortaliças ou de qualquer outra espécie vegetal.

Inicialmente, houve um primeiro contato com as educadoras da referida instituição, em que na ocasião foram relatados os objetivos propostos com as atividades da oficina. Participaram, desse momento, 34 crianças da Educação Infantil, com idades de 2 e 3 anos, além de quatro docentes da Educação Básica e quatro facilitadores do Centro de Ciências Humanas, Sociais e Agrárias da Universidade Federal da Paraíba, sendo dois discentes dos cursos de Licenciatura em Ciências Agrárias e Bacharelado em Agroecologia e dois docentes vinculados ao Departamento de Agricultura do CCHSA/UFPB.

Em sala de aula, as crianças foram questionadas se gostavam de consumir legumes e verduras, e para a surpresa dos facilitadores, houve muitas respostas positivas. Diante disso, foi perguntado quais são os vegetais que eles costumam comer e qual a estrutura da planta é responsável por originar estes vegetais. Numa linguagem clara e didática, foi possível obter respostas como: "coentro, tomate, alface, cebolinha..." e que essas plantas "surgiam da semente". Nesse sentido, foi enfatizada a importância das sementes no que diz respeito ao plantio/cultivo de olerícolas.

Na ocasião, também foi apresentado às crianças, diferentes recipientes - embalagens

reutilizáveis - de caixinhas de leite, iogurte, copos descartáveis, garrafas do tipo "pet" e garrafões de água sanitária, todos previamente lavados e perfurados na base, como uma forma de mostrar, a esses pequeninos, métodos alternativos à produção de mudas, quer seja olerícola, medicinal, ornamental ou florestal.

No pátio da escola foi desenvolvida uma ação ambiental com as crianças utilizando-se pneus, usados e descartados, de automóveis. Assim, as crianças foram conduzidas até a horta, para que pudessem preencher os pneus com substrato enriquecido com matéria orgânica e então realizar o transplantio de mudas de alface roxa, pimentão e tomate previamente 
produzidas no Viveiro do CCHSA que foram transportadas para a Escola de Educação Infantil em uma bandeja de isopor própria para a produção de mudas. Os pneus usados na horta foram coletados em oficinas mecânicas do município de Solânea/PB, por integrantes do projeto de extensão (2018) “Interagindo com a Ecologia: produção de mudas visando à conscientização ambiental" coordenado pela Prof ${ }^{\mathrm{a}}$. Gilvaneide Alves de Azeredo. Esses pneus seriam descartados, tendo o lixo como destino final. Os mesmos foram pintados de forma decorativa pela equipe do projeto citado acima. As pinturas estampadas nos pneus foram feitas utilizando-se tintas cujos galões haviam sido doados por uma loja de material de construções do mesmo município.

As crianças puderam observar mais de perto as estruturas que compõem a planta caule, folhas, raiz - além de obterem um contato mais direto com o solo. Nesse momento, algo que chamou bastante atenção foi a presença de minhocas no composto orgânico. Em seguida, os facilitadores destacaram a importância de que esses organismos apresentam à saúde do solo, através da decomposição da matéria orgânica em húmus e da criação de túneis que favorecem a aeração do solo (Figura 1).

Figura 1- Atividades de Educação Ambiental na Escola de Educação Infantil Donzinha Bezerra, Bananeiras/PB.
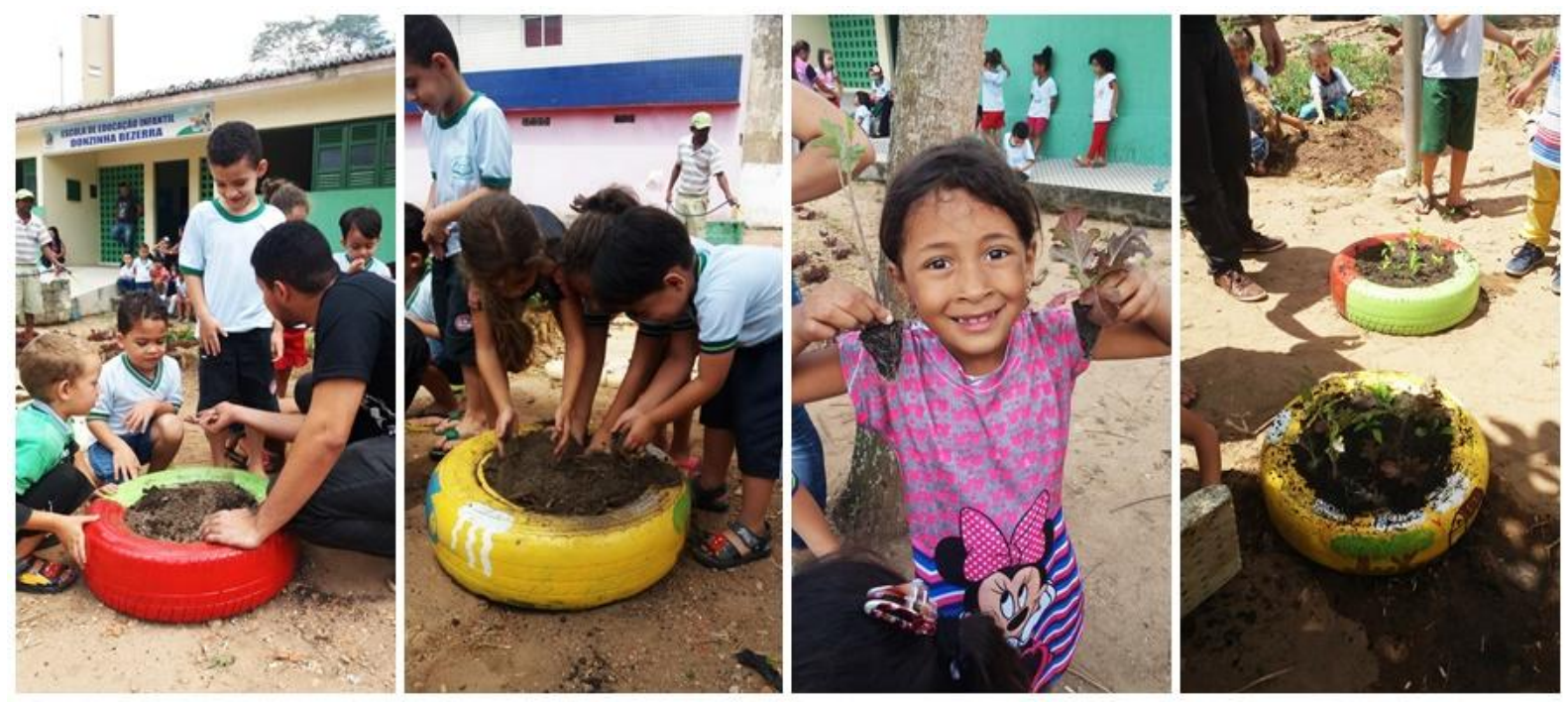

Fonte: Própria

Em um trabalho de educação ambiental a partir da construção de hortas agroecológicas com turmas da educação infantil, Carneiro et al. (2018) perceberam que os estudantes começaram a reproduzir o aprendizado teórico-prático em suas casas e com seus familiares. 
Esse ato, ainda que simbólico, resulta numa percepção mais cautelosa com o meio ambiente, e, consequentemente, na formação de indivíduos sensíveis à causa ambiental.

Em linhas gerais, a oficina proporcionou conhecimentos teórico-práticos às crianças envolvidas. Mediante a prática realizada, os estudantes compreenderam a importância de reutilizar materiais que teriam o lixo como destino final, na confecção de hortas, bem como promover uma mudança de comportamento nos hábitos cotidianos.

Ao final da oficina, os discentes agradeceram e se despediram dos facilitadores abraçando-os fortemente. $\mathrm{O}$ interesse por parte dos pequenos estudantes em relação às atividades desenvolvidas foi visivelmente perceptível, o que reflete de forma positiva na vida dos mesmos, aplicando seus conhecimentos no cotidiano.

\section{Considerações}

As práticas realizadas durante a oficina evidenciam a importância de desenvolver ações pedagógicas, envolvendo os discentes, docentes e toda a comunidade escolar no sentido de sensibilizá-los sobre os principais problemas ambientais que nos atingem, tornando-os sujeitos críticos, bem como da necessidade urgente de assumirmos uma nova postura/conduta diante da atual crise ambiental que vivemos.

\section{Referências}

BENTO, G.P.; CÂMARA, P.H.D.S.; LOPES, C.A.; SILVA, A.M.; REIS, M.C.G.; BASTIANI, M.L.R. Implantação de horta escolar em promoção da agroecologia no município de Rio Pomba, MG. Cadernos de Agroecologia, v. 13, n. 1, 2018.

CABRAL, F. F; RIBEIRO, I.de L; HRYCYK, M. F. Percepção ambiental de alunos do $6^{\circ}$ ano de escolas públicas. Revista Monografias Ambientais, Santa Maria, v. 14, n. 2, p. 151-161, 2015 .

CARNEIRO, L.M.S.; PASCHOAL, G.M.; SANTOS, D.M.P.; CARVALHO, A.P.V.; GERALDO, J.; ARRUDA, V.M. Atividades agroecológicas na educação ambiental. Cadernos de Agroecologia, v. 13, n. 1, 2018.

SOUZA, V. O.; LACERDA, C. C. O.; SILVA, N. E. F.; SILVA, L. B. Práticas ecológicas e coleta seletiva na Universidade Estadual da Paraíba. Revista de Administração, Contabilidade e Sustentabilidade (REUNIR), Sousa - PB, v. 3, n. 3, Edição Especial, p. 83-98, 2013. 